Textos 



\title{
O Judiciário como poder político no século XXI
}

\author{
ANTÔNIO DE PÁDUA RIBEIRO
}

$\mathrm{A}$

NTES DE TECER reflexões sobre o Judiciário como poder político no próximo século, convém ter presente esta observação de Maquiavel:

"Costumam dizer que os homens prudentes, e não casualmente ou sem razão, que aqueles que desejam ver o que será, ponderam sobre o que já foi: porque todas as coisas do mundo, em todo tempo, têm sua própria relação com os tempos antigos. Isso acontece porque se as coisas são feitas pelos homens, que têm e sempre tiveram idênticas paixões, é inevitável que produzam idêntico efeito" (1).

Ponderando sobre o que já foi, Montesquieu escreveu a sua célebre obra $O$ espírito das leis, consagrando uma vida que "não foi senão uma pesquisa e um magistério científico, exercido por amor dos povos". A sua obra "foi uma auto-imolação", deixando-o, ao cabo de 20 anos de labuta, debilitado e quase cego. Foi, como diria Camões, "mais do que prometia a força humana" (2). "Os meus princípios, não os tirei dos meus preconceitos, mas da natureza das coisas", assinalou o mestre no seu prefácio.

O estudo sobre a tipologia das formas de governo se perde nas brumas dos tempos. Norberto Bobbio, em uma das suas obras, descreve a célebre discussão narrada por Heródoto, entre três persas - Otanes, Megabises e Dario -, após a morte de Cambises, sobre a melhor forma de governo a adotar no seu país. Diz, com razão, que a passagem é exemplar porque traduz com clareza as três formas clássicas de governo: o de muitos, o de poucos e o de um só, ou seja, democracia, aristocracia e monarquia. Defensor do governo do povo, Otanes condena o governo de um só e o de poucos. Defensor da aristocracia, Megabises condena o governo de um só e o do povo. Por fim, Dario defende a monarquia e, ao fazê-lo, condena o governo do povo e o de uns poucos.

A diferença entre a classificação dessas formas de governo no debate narrado por Heródoto e a classificação de Aristóteles está em que, na primeira, a cada proposta tida como boa correspondem duas outras vistas como 
más, enquanto, na outra, a cada proposta boa corresponde a mesma na sua forma má: a monarquia corrompida transforma-se em tirania; a aristocracia, em oligarquia; e a democracia, em demagogia (3).

Essas formas de governo, nas idas e vindas da história, estão sempre presentes, embora algumas vezes com roupagens novas, dando razão a Maquiavel no dizer que os governos são obras de homens, que têm e sempre tiveram as mesmas paixões.

Pouco importa seja o poder exercido por um, por alguns ou por muitos. Quem o detém tende a dele abusar. O poder vai até onde encontra os seus limites. Para que os seus titulares não possam abusar dele, é preciso que, pela disposição das coisas, o poder freie o poder. Esse é o ensinamento de Montesquieu para sustentar que a liberdade política só se encontra nos governos moderados, embora não exista sempre nos Estados moderados. Ela só existe neles quando não se abusa do poder (4).

Para que um poder freie o outro, o grande clássico francês sustentou a famosa doutrina da divisão dos poderes, assinalando que "estaria tudo perdido se um mesmo homem, ou um mesmo corpo de príncipes ou nobres, exercesse esses três poderes: o de fazer as leis, o de executar as resoluções públicas e o de julgar os crimes ou demandas dos particulares” (5).

Nessa linha de entendimento, a Declaração dos Direitos do Homem e do Cidadão, de 26 de agosto de 1789, obra da Revolução Francesa e que resume a sua ideologia político-jurídica, proclamou, no seu art. 16, que "toda sociedade que não assegure a garantia dos direitos nem estabeleça a separação dos poderes, não tem constituição" (6).

A primeira aplicação prática da doutrina da divisão de poderes deu-se com a Constituição norte-americana de 17 de setembro de 1787. Daí se generalizou, sendo adotada pelo constitucionalismo dos dois últimos séculos.

Esclarece Pinto Ferreira que o sistema político brasileiro, desde a Constituição do Império, de 25 de março de 1824, recebeu a influência decisiva do pensamento teórico da distinção de poderes. Consignava a existência dos poderes clássicos, aos quais ainda agregava o poder moderador, nas mãos do 
Imperador, com o papel essencial de equilíbrio e solução dos conflitos constitucionais (7). Trata-se de importante herança do direito português.

Com a queda do Império, em 24 de fevereiro de 1891 foi promulgada a primeira Constituição republicana, estabelecendo, na consonância dos ensinamentos de Montesquieu, o sistema de três poderes, cuja estrutura básica, no tópico, permaneceu a mesma nas Constituições subseqüentes, com os hiatos decorrentes do regime político corporificado na Carta outorgada em 10 de novembro de 1937 e durante o período de excepcionalidade da Revolução de 1964.

A Constituição em vigor, promulgada em 5 de outubro de 1988, diz no seu art. $2^{\circ}$ que "são Poderes da União, independentes e harmônicos entre si, o Legislativo, o Executivo e o Judiciário". No seu título IV, que versa sobre a organização dos Poderes, destina um capítulo a cada Poder, referindo-se o capítulo III ao Poder Judiciário.

O Judiciário no Brasil é, pois, um Poder do Estado. O Estado brasileiro consubstancia-se numa República Federativa, formada pela união indissolúvel dos estados e municípios e do Distrito Federal. Constitui-se em Estado democrático de direito e tem como fundamentos a soberania, a cidadania, a dignidade da pessoa humana; os valores sociais do trabalho e da livre iniciativa e o pluralismo político. Todo o poder emana do povo, que o exerce por meio de representantes eleitos ou diretamente, nos termos da Constituição ( art. $1^{\circ}$ e parágrafo único).

Constituem objetivos fundamentais da República Federativa do Brasil: construir uma sociedade livre, justa e solidária; garantir o desenvolvimento nacional; erradicar a pobreza e a marginalização e reduzir as desigualdades sociais e regionais; e promover o bem de todos, sem preconceitos de origem, raça, sexo, cor, idade e quaisquer formas de discriminação.

No exercício das suas atribuições, o Judiciário há de ter sempre presentes esses princípios fundamentais.

A independência do Judiciário, sem prejuízo da sua atuação harmônica com os outros Poderes, é assegurada pela Constituição, que lhe dá autonomia administrativa e financeira e estabelece as garantias da magistratura (arts. 95, 99 e 168). 
Os Tribunais elaboram e encaminham as suas propostas orçamentárias ao Congresso Nacional, com observância dos limites estipulados conjuntamente com os demais Poderes na lei de diretrizes orçamentárias. Os recursos correspondentes às dotações orçamentárias que lhes são destinadas, compreendidos os créditos suplementares e especiais, lhes são entregues, em duodécimos, até o dia 20 de cada mês.

Aos juízes são asseguradas as garantias da vitaliciedade, sujeitos, porém, à aposentadoria compulsória aos 70 anos, inamovibilidade e irredutibilidade de subsídio.

São órgãos do Poder Judiciário: o Supremo Tribunal Federal; o Superior Tribunal de Justiça; os tribunais regionais federais e juízes federais; os tribunais e juízes do trabalho; os tribunais e juízes eleitorais; os tribunais e juízes militares; e os tribunais e juízes dos estados e do Distrito Federal e territórios (art. 92).

Há dois Tribunais da Federação, ou seja, que exercem jurisdição sobre a Justiça comum federal e estadual: O Supremo Tribunal Federal, corte predominantemente constitucional, órgão de cúpula de todo o Judiciário, incluindo a justiça especializada (militar, eleitoral e do trabalho), e o Superior Tribunal de Justiça, órgão de cúpula da Justiça comum federal e estadual, a que cabe zelar pela autoridade e uniformidade interpretativa do direito federal.

É diante desse contexto, que descreve, em resumo, o Judiciário brasileiro no âmbito histórico e no concerto das Nações, que cumpre refletir sobre ele como poder político no próximo século sob a ótica dos magistrados.

No tocante ao posicionamento do Judiciário como poder político do Estado, o que se espera, no Brasil, é a manutenção das mesmas regras e princípios hoje existentes, que igualam ou até mesmo superam em conquistas as já obtidas por outros importantes Estados democráticos de direito.

O problema está em colocar em prática esses princípios, de maneira a tornar o exercício das funções jurisdicionais menos moroso e mais eficiente, tendo em conta que o Judiciário presta serviço público de alta relevância, qual seja, aquele de distribuir justiça.

É preciso ter-se em conta que, numa república democrática, o governo é das leis e não dos homens. A respeito, examinando o assunto com a profundidade que lhe é peculiar, conclui Bobbio: "Se então, na conclusão 
da análise, pedem-me para abandonar o hábito do estudioso e assumir o do homem engajado na vida política do seu tempo, não tenho nenhuma hesitação em dizer que a minha preferência vai para o governo das leis, não para o governo dos homens. O governo das leis celebra hoje o próprio tempo da democracia. E o que é a democracia senão um conjunto de regras (as chamadas regras do jogo) para a solução dos conflitos sem derramamento de sangue? E em que consiste o bom governo democrático se não, acima de tudo, no rigoroso respeito a estas regras? Pessoalmente, não tenho dúvida sobre a resposta a estas questões. E exatamente porque não tenho dúvidas, posso concluir tranqüilamente que a democracia é o governo das leis por excelência. No momento mesmo em que um regime democrático perde de vista este seu princípio inspirador, degenera rapidamente em seu contrário, numa das tantas formas de governo autocrático de que estão repletas as narrações dos historiadores e as reflexões dos escritores políticos" (8).

Em termos de garantias jurisdicionais dos cidadãos, relativamente à administração da justiça, a vigente Constituição brasileira adota como postulado constitucional fundamental o "devido processo legal", expressão oriunda da inglesa due process of law, ao dizer: "ninguém será privado da liberdade ou de seus bens sem o devido processo legal" (art. $5^{\circ}$, LIV). Adota, ainda, o princípio da inafastabilidade do controle jurisdicional, ao estatuir que "a lei não excluirá da apreciação do Poder Judiciário lesão ou ameaça a direito" (art. 5, $\mathrm{XXXV})$. Consagra o princípio da isonomia: "Todos são iguais perante a lei, sem distinção de qualquer natureza, garantindo-se aos brasileiros e aos estrangeiros residentes no país a inviolabilidade do direito à vida, à liberdade, à igualdade, à segurança e à propriedade"; "homens e mulheres são iguais em direitos e obrigações, nos termos desta Constituição" (art. $5^{\circ}$, caput e inciso I). Estabelece, ainda, o princípio do juiz ou promotor natural, ao dizer que "não haverá juízo ou tribunal de exceção", e que "ninguém será processado nem sentenciado senão pela autoridade competente" (art. $5^{\circ}$, XXXVII e LIII). Estatui o princípio do contraditório: "aos litigantes, em processo judicial ou administrativo, e aos acusados em geral são assegurados o contraditório e ampla defesa, com os meios e recursos a ela inerentes" (art. $\left.5^{\circ}, \mathrm{LV}\right)$. Prevê o princípio da proibição da prova ilícita: "são inadmissíveis, no processo, as provas obtidas por meios ilícitos" (art. 5 , LVI); o princípio da publicidade dos atos processuais: "todos os julgamentos dos órgãos do Poder Judiciário serão públicos" (art. 93, IX), acrescentando que "a lei só poderá restringir a publicidade dos atos processuais quando a defesa da intimidade ou o interesse social o exigi- 
rem" (art. $\left.5^{\circ}, \mathrm{LX}\right)$; e o princípio da motivação das decisões judiciais sob pena de nulidade (art. 93, IX).

O Estado está em crise; e a sua atuação, em dissonância com o que dele esperam os cidadãos. Nesta época de globalização e liberalismo econômico, acerbas críticas são dirigidas aos entes públicos, ao fundamento de que não funcionam a contento a serviço da coletividade e de que se têm esquecido da sua finalidade precípua, qual seja, a de realizar o bem comum e, em decorrência, ajudar a população a alcançar a sua grande aspiração, que é a de toda a Humanidade: efetivar o sonho de ser feliz.

A crise do Estado decorre da gritante disparidade entre a demanda social e a resposta política. Hoje, não se pede ao Estado apenas proteção, mas muito mais que isso, e ele não tem poder suficiente para realizar o que dele se espera.

A deficiente estrutura do Estado, inadequada para atender às suas finalidades, gera excesso de regulamentação e de atos administrativos ensejadores de conflitos com os particulares (funcionários públicos, beneficiários da previdência social, empresas etc.). São litígios fundados na legislação estatutária, previdenciária, tributária e financeira. Aquela deficiência enseja ainda a contínua edição de leis, muitas delas aprovadas e mal redigidas, causadoras de insegurança jurídica e, em decorrência, de litígios. Esses litígios ou lides, em número avassalador, vão sobrecarregar o Judiciário, estendendo-lhe as conseqüências da crise do Estado (9).

A Lei e a Justiça “compõem as duas faces deste universo sobre o qual gravitam todos os fenômenos jurídicos". Há uma crise da Lei e uma crise da Justiça. Essas crises decorrem da "distorção entre a lei e os anseios sociais" e da "ineficiência da realização da justiça." Daí que, com inteira pertinência, destacou o desembargador Luiz Fux que "resplandece no céu do terceiro milênio, encartada numa das 'Eras do Direito', idealizadas pelo notável Norberto Bobbio, a 'Era da Legitimidade', resultante das novas expectativas quanto à 'lei e à justiça', emergentes das respostas à crise jurídica que agoniza no mundo que ora contemplamos”.

É o citado magistrado e professor, ainda, quem realça que a "crise judicial confina com a crise da lei", assinalando que, "em outra medida, a 'justiça da decisão' depende da 'justiça legal', porquanto o magistrado tem como atividade precípua a submissão dos fatos às normas" (10). 
E, após dizer que “uma sentença em que se constrói o 'jurídico’ antes do 'justo' se equipara a uma casa onde se erige o teto antes do solo", endossando Plauto Faraco de Azevedo, preconiza a era de um poder judicial criativo "que atenda às exigências de justiça perceptíveis na sociedade e compatíveis com a dignidade humana, um poder para cujo exercício o juiz se abra ao mundo ao invés de fechar-se nos códigos, interessando-se pelo que se passa ao seu redor, conhecendo o rosto da rua, a alma do povo, a fome que leva o homem a viver no limiar da sobrevivência biológica" (11).

Os conflitos multiplicam-se na sociedade e, a cada instante, os cidadãos estão a clamar por justiça. Freqüentemente, os jornais se referem aos sem-terra, aos sem-teto, aos que reclamam por assistência médica, por educação, por emprego.

Tais conflitos, de origem geral, precisam ser solucionados, mas a sua justa solução pressupõe sempre a opção por valores que, num determinado momento, devem prevalecer.

O deslinde desses conflitos ocorre mediante a atuação dos Poderes do Estado: o Executivo, o Legislativo e o Judiciário. Portanto a Justiça, em termos estatais, não é praticada só pelo Judiciário, mas também pelos outros Poderes. Ao Judiciário cabe solucionar apenas certos conflitos especiais, denominados litígios ou lides.

Essas distinções são feitas porque o Judiciário, hoje, é intensamente criticado e, com freqüência, de forma injusta. Muitas vezes dele se exige uma justiça que não pode praticar. Essas limitações, nem sempre notadas por pessoas que se dizem letradas, foram percebidas, com percuciência, pelo representante dos trabalhadores rurais, homem simples, mas catedrático na luta pela vida, em importante simpósio sobre a reforma do Poder Judiciário, no qual os temas pertinentes eram debatidos com amplos setores da sociedade. Disse ele, referindo-se à reforma agrária, com sabedoria e de maneira respeitosa, aos representantes do Judiciário presentes: “A Justiça que nós queremos, vocês não a podem nos dar.”

É preciso, porém, repensar o Judiciário, objetivando a adoção de providências no sentido da efetividade dos direitos e da cidadania, na certeza de que justiça lenta e à qual tem acesso apenas parte da população é injusta. E, no desempenho dessa tarefa, impõe considerar não apenas, como até aqui 
tem acontecido, os operadores do sistema judiciário, mas especialmente os consumidores da justiça. Não se pode olvidar que, no regime democrático, a atuação precípua do Estado, mediante os seus órgãos, há de visar sempre à afirmação da cidadania. De nada adianta conferirem-se direitos aos cidadãos, se não lhes são dados meios eficazes para a concretização desses direitos.

As idéias sobre a matéria vêm sendo desenvolvidas em países da Europa e da América, em torno do que se convencionou chamar "acesso à justiça", sendo relevantes a respeito os sucessivos trabalhos publicados por Mauro Cappelletti e Vittorio Denti.

Em suma, o que pretende essa corrente de pensamento é "a abertura da ordem processual aos menos favorecidos da fortuna e à defesa de direitos e interesses supra-individuais, com a racionalização do processo", que "quer ser um 'processo de resultados', não um processo de conceitos ou de filigranas" (12). O que se almeja é a efetividade do processo, sendo indispensável, para isso, "pensar no processo como algo dotado de bem definidas destinações institucionais e que deve cumprir os seus objetivos sob pena de ser menos útil e tornar-se socialmente ilegítimo" (13). Acesso à justiça é o “acesso à ordem jurídica justa”, no dizer de Kazuo Watanabe. "Não tem acesso à justiça aquele que sequer consegue fazer-se ouvir em juízo, como também todos os que, pelas mazelas do processo, recebem uma justiça tarda ou alguma injustiça de qualquer ordem" (14).

Em brilhantes conferências a respeito do tema, assinalou o professor Mauro Cappelletti ser muito fácil declarar os direitos sociais; o difícil é realizálos. Daí que "o movimento para acesso à justiça é um movimento para a efetividade dos direitos sociais", e a sua investigação deve ser feita sob três aspectos principais, a que denominou ondas renovatórias: a primeira referese à garantia de adequada representação legal dos pobres. Como fazê-la? A designação honorífica de advogados não tem mais sentido. Deve-se permitir a escolha de profissionais, instituir órgãos de defensoria pública ou adotar-se sistema misto? Seja qual for a solução, é fundamental que se assegure aos necessitados assistência jurídica, integral e gratuita (15).

A segunda onda renovatória visa à tutela dos interesses difusos ou coletivos, com o objetivo de proteger o consumidor ou o meio ambiente. Pressupõe que o conceito de pobreza não se adstringe ao indivíduo carente de recursos financeiros, ou de cultura, ou de posição social. É mais vasto: abrange grupos e categorias, como no caso do consumidor. Uma empresa produz milhões de produtos com um defeito de pouco valor. Trata-se de 
interesse fragmentado, pequeno demais para que o cidadão, individualmente, defenda o seu direito. Mas, se todos os consumidores, em conjunto, decidirem atuar, estarão em jogo interesses consubstanciados em valores consideráveis. Há, pois, de atentar-se para os carentes econômicos e para os carentes organizacionais.

A terceira onda preocupa-se com fórmulas para simplificar os procedimentos, o direito processual e o direito material, como, por exemplo, nas pequenas causas, a fim de que o seu custo não seja superior ao valor pretendido pelo autor. O tema envolve estudos, entre outros, sobre o princípio da oralidade e da imediatidade, bem como sobre os poderes do juiz e sobre a instrumentalidade do processo.

Em síntese, segundo o insigne jurista, os principais problemas do movimento reformador são os seguintes:

“a) o obstáculo 'econômico', pelo qual muitas pessoas não estão em condições de ter acesso às cortes de justiça por causa de sua pobreza, aonde seus direitos correm o risco de serem puramente aparentes;

b) o obstáculo 'organizador', através do qual certos direitos ou interesses 'coletivos' ou 'difusos' não são tutelados de maneira eficaz se não se operar uma radical transformação de regras e instituições tradicionais de direito processual, transformações essas que possam ter uma coordenação, uma 'organização' daqueles direitos ou interesses;

c) finalmente, o obstáculo propriamente 'processual', através do qual certos tipos tradicionais de procedimentos são inadequados aos seus deveres de tutela."

Com apoio nos textos constitucionais em vigor, importantes leis têm sido promulgadas com o objetivo de tornar realidade as novas regras atinentes ao que se denominou "acesso à justiça”. Nesse sentido, incluem-se aquelas relativas à reforma do Código de Processo Civil.

No Brasil, essa grande transformação começou, no plano legislativo, com a edição da Lei da Ação Popular (Lei n. ${ }^{\circ} 4.717$, de 29/6/1965) e assumiu dimensões revolucionárias com a promulgação da Lei da Ação Civil Pública (Lei n. ${ }^{\circ} 7.347$, de $24 / 7 / 1985$ ), estendida até mesmo à tutela da ordem econômica pela Lei n. ${ }^{\circ} 8.884$, de 11/6/1994, (art. 88), Estatuto da Criança e do Adolescente (Lei n. ${ }^{\circ} 8.069$, de 13/7/1990) e Código de Defesa do Consumidor (Lei n. ${ }^{\circ} 8.078$, de 11/9/1990). 
A Lei da Ação Civil Pública, o Estatuto da Criança e do Adolescente e o Código de Defesa do Consumidor instituíram as bases da tutela do direito coletivo em nosso ordenamento jurídico. Esses diplomas legais atribuíram legitimidade ao Ministério Público e a outras entidades representativas de classe, estabeleceram regras sobre a coisa julgada erga omnes e ultra partes e dispuseram sobre a conceituação das três espécies de direitos e interesses a serem objeto de tutela coletiva: os difusos, os coletivos e os individuais homogêneos.

Ressalte-se que a Constituição Federal em vigor, no plano da tutela constitucional das liberdades, criou os institutos do habeas data, do mandado de injunção e do mandado de segurança coletivo, consagrando princípios relativos à tutela jurisdicional coletiva (legitimidade dos sindicatos e das entidades associativas em geral: art. $5^{\circ}$, inciso XXI, e art. $8^{\circ}$, inciso III) e dando feição constitucional aos Juizados Especiais de Pequenas Causas (art. 24 , inciso X, e art. 98, inciso I) e à ação civil pública (art. 129, inciso III).

Com essa nova visão, foi recentemente promulgada a Lei n. ${ }^{\circ} 9.099$, de 26/9/1995, que dispõe sobre os Juizados Especiais Cíveis e Criminais, cujo art. $2^{\circ}$ estabelece os seus princípios básicos: oralidade, simplicidade, informalidade, economia processual e celeridade, buscando, sempre que possível, a conciliação ou a transação. O significativo número das demandas transindividuais ajuizadas, fundadas na legislação antes referida, mostra a boa acolhida que vem obtendo da sociedade e a sua grande utilidade para a população e para a defesa do interesse público.

Cumpre assinalar, outrossim, que os meios alternativos de solução de litígios devem ser difundidos, estimulando-se o uso da mediação, da conciliação e da arbitragem. A respeito, foi promulgada a Lei n. ${ }^{\circ}$ 9.307, de 23/ 9/1996, também denominada "Lei Marco Maciel".

Dentro desse quadro, algumas questões importantes devem ser enfrentadas e solucionadas ou, pelo menos, equacionadas na chamada reforma do Poder Judiciário, que não se adstringe ao plano constitucional.

Entre as providências que vêm sendo debatidas e efetivadas, creio seja conveniente adotar concretamente a denominada justiça itinerante, voltada às populações mais carentes das periferias das grandes metrópoles e da zona rural, e a ampliação dos juizados especiais de pequenas causas, estendendoos à União Federal (17). Enfim, é imperioso que se criem mecanismos, visando dar mais flexibilidade à administração da justiça.

A preocupação que se deve ter presente é a de afastar o "sentimento de deslegitimação por parte da maioria da população" com que depara o 
Poder Judiciário. É preciso dar meios aos excluídos e aos pobres para que deixem de recorrer a outros canais de mediação, como a polícia, o padre, o líder comunitário e o justiceiro. Ou seja, cumpre dar condições a toda a população para assegurar de fato a sua cidadania.

O Estado social, que emergiu no curso deste século, num panorama de tensões, crises e controvérsias, é caracterizado pela expansão sem precedentes dos Poderes do Estado legislador e administrador. Daí que se tornou mais aguda e urgente a exigência do controle judiciário da atividade do Estado. As lides deixaram de envolver apenas sujeitos privados e passaram a comprometer os Poderes políticos do Estado.

Por outro lado, a expansão da função legislativa e o crescente volume de legislação, além de sobrecarregarem os parlamentos, ensejaram a edição de leis ambíguas e vagas, deixando delicadas escolhas políticas à fase da sua interpretação e aplicação. Acrescente-se, ainda, a existência de massa de leis que continuam "nos livros" mesmo depois de se tornarem obsoletas. Esses eventos ensejaram a necessidade de um ativismo judicial mais acentuado, mas não são considerados pelos críticos desse ativismo.

A tudo isso se acrescenta o fato de que, em regra, os direitos sociais são "promocionais" e voltados para o futuro, exigindo para a sua gradual realização a intervenção ativa e prolongada no tempo pelo Estado. Ao aplicar as leis pertinentes, o juiz não pode proceder de maneira estática, mas deve ter presente a finalidade social da lei à vista dos programas prescritos de maneira vaga pelas referidas normas.

Finalmente, assumem cada vez mais significação os conflitos decorrentes do fenômeno da "massificação", especialmente a tutela dos denominados interesses difusos, homogêneos ou coletivos. Isso está a exigir uma nova visão dos conceitos e regras do processo judicial e do próprio papel do juiz moderno (17).

Sob o citado ângulo de visão, é também possível verificar que a crise do Judiciário é um aspecto da crise do próprio Estado. Sem se organizar e dar eficiência ao Estado-administrador e ao Estado-legislador, deficiente continuará o Estado-justiça.

Convém, por isso mesmo, na atual conjuntura, que se aumente a co- 
laboração entre os Poderes do Estado, objetivando apressar soluções tendentes ao bem comum. Não se trata de abrir mão dos princípios que regem a atuação de cada Poder, mas de uma aproximação maior entre os seus membros com o fito de se tomarem medidas de interesse geral, visando à sociedade como um todo. O que se há de procurar é dar cumprimento à segunda parte do art. $2^{\circ}$ da Constituição, segundo o qual os Poderes são independentes, mas harmônicos entre si. Ou seja, a independência não exclui a harmonia, e a harmonia só poderá ser obtida mediante conversações que permitam identificar as posições convergentes sobre os problemas do Estado, a fim de que possam ser superados com a velocidade dos tempos modernos.

Não se deve olvidar que, à semelhança do que acontece com a atividade dos juízes, dos membros do Ministério Público e dos advogados, o relacionamento entre os Poderes obedece ao sistema dos vasos intercomunicantes. O Estado só funciona bem quando as suas atividades fundamentais são exercidas harmonicamente, sem dolo, sem malícia, em nível ético. Um poder que, pela atuação dos seus agentes, falta ao respeito ao outro ignora o que não pode desconhecer: não se pode baixar o nível de um, sem baixar, de igual modo, o do outro (18). E, no que concerne ao mútuo respeito, "inexiste o mais alto: o respeito não desce de cima para baixo, não sobe de baixo para cima. Horizontalmente se manifesta sempre. Interligam-se de tal modo os três, que a elevação de um a todos enobrece, assim como o desrespeito a um a todos atinge" (19).

O Estado proibiu a autotutela, punindo como crime fazer justiça pelas próprias mãos. Assumiu, pois, o compromisso de solucionar, de forma adequada, efetiva e em tempo hábil, os litígios ou lides que ocorrem no seio da sociedade. O processo, mediante o qual atua a sua função jurisdicional, deve ensejar resultado semelhante ao que se verificaria se a ação privada não estivesse proibida (20).

É relevante ter-se em conta que “a demora da resposta judicial leva ao exaurimento de forças à parte débil que, diferentemente do litigante mais portentoso, não tem condição de arcar com essa lentidão permitindo aquele arrancar-lhe vantajosas concessões. Por essa razão, Cappelletti, curvado sobre o problema, cedeu à realidade ao concluir: 'a justiça é igual para todos, mas um pouco mais igual para os ricos e um pouco menos igual para os pobres" $"(21)$. 
A Convenção Européia para Proteção dos Direitos Humanos e Liberdades Fundamentais estabeleceu, no seu art. $6^{\circ}, \mathfrak{S} 1^{\circ}$, que a Justiça que não cumpre suas funções dentro de "um prazo razoável” é, para muitas pessoas, uma justiça inacessível (22).

Nessa perspectiva, é intuitivo que "a inexistência de tutela 'adequada' a determinada situação conflitiva corresponde à própria negação da tutela a que o Estado se ‘obrigou' quando chamou a si o monopólio da jurisdição”. Daí a necessidade de tutelas rápidas e imediatas para remediar a ineficácia do procedimento ordinário e da própria administração da justiça (23).

Impõe-se, pois, que o legislador e o juiz do terceiro milênio tenham "em mente que 'as situações de periclitação e as de evidência' merecem tutela imediata. A primeira, em face da possibilidade de dano irreparável acaso a justiça não seja imediata. A segunda, porque, em face de um 'direito líquido e certo', não se revela justo o aguardar indefinido de uma resposta judicial, que não pode ser outra senão aquela que acompanha a prova inequívoca que conduz à verossimilhança e à probabilidade de êxito alegado pela parte”. Ademais, "as sentenças devem valer por si sós, sem necessidade de atividades complementares que impliquem nova e delongada relação processual. A auto-executividade e mandamentalidade das decisões é anseio cuja contemplação não pode ultrapassar a 'nova era' sem a correspondente consagração” (24).

No Brasil, as alterações do Código de Processo Civil, introduzidas pela Lei n. ${ }^{\circ} 8.952$, de 13/12/1994, prestigiaram a doutrina da criação de tutelas diferenciadas, inclusive das tutelas de evidência. Quanto a estas últimas, passou a contemplar aquela lei duas modalidades de antecipação de tutela: uma relativa a obrigações de dar (art. 273) e outra às obrigações de fazer e não fazer (art. 461) (25).

Continuam, porém, as dificuldades de cumprimento das sentenças condenatórias. Não há tipificação criminal e, por isso, prisão por “descumprimento de ordem judicial" ou "desacato judicial". No direito anglo-saxão, a prisão por dívida é vedada, mas isso não afasta aquela decorrente do descumprimento voluntário e afrontoso de ordens judiciais.

Cumpre encerrar. Levantei numerosas questões sobre o Judiciário, mas não é fácil dizer como solucioná-las. O importante é tê-las presentes, é ter delas consciência, a fim de que, no momento próprio, possam ser superadas. É, ainda, imperioso que os estudiosos trabalhem conscientes de que, 
nesta época em que tudo se questiona, não podem olvidar o tema sobre a legitimidade do Judiciário como Poder, sob o enfoque da sua aceitação pela sociedade a que serve. É indispensável a mudança de mentalidade e a criatividade, a fim de que novos princípios sejam aplicados à solução dos litígios, mitigando-se, assim, o fenômeno da litigiosidade contida e da impunidade, que, como doença insidiosa, pode aflorar com todas as suas energias funestas e atingir os alicerces que sustentam a causa democrática. $\mathrm{O}$ Judiciário só se impõe como verdadeiro poder no Estado de direito. Por isso mesmo que, quando a democracia floresce, assume a sua verdadeira dimensão de órgão do Estado que equilibra a atuação das forças vivas da nacionalidade, reduzindo os inevitáveis conflitos decorrentes das concepções antagônicas sobre os fatos da vida e mostrando aos cidadãos o caminho do entendimento e da harmonia, sem o qual seremos forçados a volver às formas de convivência ultrapassadas, próprias dos períodos mais obscuros registrados pela História.

Notas

1 N. Machiavelli. Discorsi, III, 43.

2 Os Lusíadas. Conto I, 29. Saraiva. 1982, p. 5-6. Ver a Introdução sobre a tradução do Espírito das Leis, escrita pelo desembargador Pedro Vieira Mota.

3 Ver Teoria das formas de governo, $9^{2}$ ed., UnB, p. 39-43.

4 O espirito das leis. Saraiva, 1987, p. 163, tradução de Pedro Vieira Mota.

5 Obra citada, p. 165.

6 Este o texto francês: “Toute société dans laquelle la garantie des droits n'est pas assurée, ni la séparation des pouvoirs déterminée, n'a point de constitution”.

7 Ver Teoria geral do Estado, $2^{\circ}$ v, $3^{\mathrm{a}}$ ed., Saraiva, 1975, p. 743.

8 O futuro da democracia, $5^{\text {a }}$ ed., Paz e Terra, p. 170-171, tradução de Marco Aurélio Nogueira.

9 Ver Sálvio de Figueiredo Teixeira. As tendências brasileiras rumo à jurisprudência vinculante. Informativo Jurídico da Biblioteca Oscar Saraiva, v. 10, 1998, p. 143-149.

$10 \mathrm{O}$ que se espera do Direito no terceiro milênio, frente às crises das leis, da justiça e do ensino jurídico, aula magna proferida em 31.8.1998, Universidade Gama Filho. 
11 Id.

12 Cândido Ragel Dinamarco. A reforma do Código de Processo Civil, $4^{\mathrm{a}}$ ed. Malheiros, 1998, p. 21-22.

$13 I d$.

$14 I d$

15 No Brasil, a Constituição estabelece que "o Estado prestará assistência judicial integral e gratuita aos que comprovarem insuficiência de recursos" (art. 5 LXXIV), esclarecendo que "A Defensoria Pública é instituição essencial à função jurisdicional do Estado, incumbindo-lhe a orientação jurídica e a defesa, em todos os graus, dos necessitados" (art. 134).

16 Emenda Constitucional n. 22, promulgada em 18.3.1999, art. $1^{\circ}$.

17 Discurso de posse na Presidência do STJ, separata, p. 10.

$18 \mathrm{O}$ enfoque foi utilizado por Piero Calamandrei na comparação das atividades entre juízes, advogados e membros do Ministério Público, e não entre os Poderes do Estado. Ver Eles, os juizes, vistos por nós, os advogados, $4^{\mathrm{a}}$ ed., Clássica, p. 22. O texto consta no meu discurso de posse na Presidência do Superior Tribunal de Justiça, ocorrida em 2/4/1998.

19 A expressão foi usada pelo ilustre advogado doutor. Justino Vasconcelos, ao falar sobre "Advocacia e relacionamento com a Magistratura e o Ministério Público", tese n. ${ }^{\circ}$ 12, VI Conferência Nacional da OAB, Salvador (BA), outubro de 1978. Não se referiu o autor ao relacionamento entre os Poderes do Estado. O texto consta no meu discurso de posse antes citado.

20 José Carlos Barbosa Moreira, tutela sancionatória e tutela preventiva, in: Temas de Direito Processual (segunda série). São Paulo, Saraiva, 1980, p. 21. Luiz Guilherme Marinoni, Efetividade do Processo e Tutela de Urgência. Sérgio Antônio Fabris Editora, 1994, p. 12.

21 Desembargador Luiz Fux, aula magna citada, p. 26-27.

22 Mauro Cappelletti \& Bryant Garth. Acesso à Justiça. Sérgio Antônio Fabris Editora, 1988, p. 20-21, tradução de Ellen Gracie Northfleet.

23 Luiz Guilherme Marinoni. Obra citada, p. 66.

24 Desembargador Luiz Fux, aula magna citada, p. 28- 29. O tema é desenvolvido pelo ilustre autor na tese em que obtém a titularidade de Direito Processual Civil da UERJ: Tutela de segurança e tutela de evidência.

25 V.E. Carreira Alvim. Tutela específica das obrigações de fazer e não fazer. Del Rey, 1997, p. 9-10. 
RESUMO - O ESTUDO versa sobre a filosofia das formas de governo e refere-se à doutrina dos freios e contrapesos, mostrando a necessidade de distinção entre os Poderes do Estado. Resume-se a estrutura anterior e atual do Poder Judiciário brasileiro, citando os princípios constitucionais e as garantias jurisdicionais dos cidadãos. Diz haver crise da Lei e da Justiça. Preocupa-se com a efetividade dos direitos e da cidadania e enfoca o tema sobre a legitimidade do judiciário como Poder, sob o prisma da sociedade a que serve. Para enfrentar a crise do Estado, da qual a crise do Judiciário é um aspecto, conclui ser indispensável a mudança de mentalidade e a criatividade.

ABSTRACT - THIS PAPER deals with the philosophy of government forms and refers to the brake and counterbalance doctrine, showing the necessity to establish a distinction between State Powers. The past and present structure of the Brazilian Justice are summarized and the constitutional principles and the citizens'jurisdicional guarantees are mentioned. A Law and Justice crisis is identified. Worries are expressed concerning the effectiveness of civil rights and the legitimacy of the judiciary as a Power is focused on from the point of view of the society it serves. The paper concludes that in order to face the State crisis, of which the judiciary is an aspect, a mentality change and creativeness are necessary.

Antônio de Pádua Ribeiro, juíz, é presidente do Superior Tribunal de Justiça.

Conferência feita pelo autor no Congresso Brasil-Portugal Ano 2000, realizado em Coimbra, Portugal, no dia 23 de junho de 1999. 